\title{
El emprendimiento social de base universitaria en Latinoamérica: caso Zacatecas, México
}

\author{
University-Based Social Entrepreneurship in Latin America. The Zacatecas
}

(México) case

Empreendedorismo social baseado em universidades na América Latina: o caso Zacatecas, México

Víctor Hugo Bañuelos García

Universidad Autónoma de Zacatecas, México

bag_70@hotmail.com https://orcid.org/0000-0003-0888-4157

Flor de María García Martínez

Universidad Autónoma de Zacatecas, México

florecitagama@hotmail.com https://orcid.org/0000-0003-3869-0169

Rubén Carlos Álvarez Diez

Universidad Autónoma de Zacatecas, México

ruben@unizacatecas.edu.mx https://orcid.org/0000-0002-0877-2238 


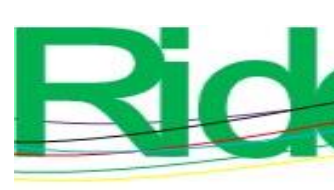

Revista Iberoamericana para la Investigación y el Desarrollo Educativo ISSN $2007-7467$

\section{Resumen}

La globalización exige que los egresados de la educación superior cuenten con habilidades que impacten en el desarrollo económico. Y una de las habilidades más apreciadas actualmente es el emprendimiento social. La presente investigación está precedida por el trabajo denominado El emprendimiento social de base universitaria en Latinoamérica, en el cual se encontró que solo $3.4 \%$ de los 5243 estudiantes encuestados de 26 universidades de ocho países está liderando algún emprendimiento social, esto a pesar de que $62 \%$ desea hacerlo. El propósito del presente estudio fue comparar los resultados del contexto internacional con el local. Para ello, se partió del modelo de ecuaciones estructurales usado en el estudio previo. Se aplicó un cuestionario a una muestra de 301 alumnos de la Unidad Académica de Contaduría y Administración de la Universidad Autónoma de Zacatecas. En los resultados se encontró que solo $0.7 \%$ de ellos lidera un emprendimiento social. Se concluye que falta mucho por hacer por parte de la institución educativa, ya que el constructo "Soporte institucional" no contribuyó de manera significativa en la intención emprendedora. Sin duda es pertinente generar acciones que permitan a los alumnos llevar a cabo proyectos y que estos no queden en intenciones.

Palabras clave: emprendimiento social, liderazgo, universidad.

\section{Abstract}

Globalization requires that graduates of higher education have skills that impact economic development. And one of the most appreciated skills today is social entrepreneurship. This research is preceded by the work titled University-based social entrepreneurship in Latin America, in which it was found that only $3.4 \%$ of the 5243 students surveyed from 26 universities in 8 countries are leading some social entrepreneurship, this despite the fact that $62 \%$ wants to. The purpose of the present study was to compare the results of the international context with the local one. For this, we started from the structural equations model used in the previous study. A questionnaire was applied to a sample of 301 students from the Unidad Académica de Contaduría y Administración of the Universidad Autónoma de Zacatecas. In the results it was found that only $0.7 \%$ of them lead a social enterprise. It is concluded that much remains to be done by the educational institution, since the construct "Institutional support" did not contribute significantly to the entrepreneurial intention. 


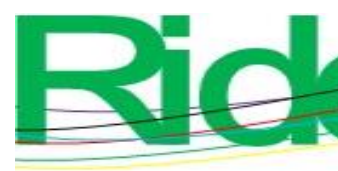

Revista Iberoamericana para la
Investigación y el Desarrollo Educativo
ISSN $2007-7467$

Without a doubt, it is pertinent to generate actions that allow students to carry out projects and that these do not remain intentions.

Keywords: social entrepreneurship, leadership, university.

\section{Resumo}

A globalização exige que os graduados do ensino superior tenham habilidades que impactam o desenvolvimento econômico. E uma das habilidades mais apreciadas hoje é o empreendedorismo social. Esta pesquisa é precedida do trabalho denominado Empreendedorismo social de base universitária na América Latina, no qual se constatou que apenas 3,4\% dos 5243 alunos pesquisados de 26 universidades de oito países lideram algum empreendedorismo social, isto apesar de $62 \%$ quer. O objetivo do presente estudo foi comparar os resultados do contexto internacional com o local. Para isso, partimos do modelo de equações estruturais utilizado no estudo anterior. Foi aplicado um questionário a uma amostra de 301 alunos da Unidade Académica de Contabilidade e Administração da Universidade Autónoma de Zacatecas. Nos resultados constatou-se que apenas 0,7\% deles lideram um empreendimento social. Conclui-se que muito ainda precisa ser feito pela instituição de ensino, visto que o construto "Apoio institucional" não contribuiu significativamente para a intenção empreendedora. Sem dúvida, é pertinente gerar ações que permitam aos alunos realizar projetos e que estes não fiquem intencionais.

Palavras-chave: empreendedorismo social, liderança, universidade.

Fecha Recepción: Julio 2020

Fecha Aceptación: Enero 2021

\section{Introducción}

Las competencias profesionales de los egresados del nivel superior demandan más dominio de contenidos disciplinares. Los retos de un mundo complicado y globalizado hacen ineludible que en el contexto universitario se desarrollen habilidades que les serán ventajosas para impactar en el desarrollo económico de su entorno social. Si bien el emprendimiento ha ocupado a investigadores desde mediados del siglo XVIII, no fue sino hasta en la década de 1950 que en Estados Unidos abordaron este fenómeno con mayor detenimiento, ya que la evidencia revelaba que aún las empresas más consistentes no estaban exentas de la bancarrota. En la década de 1980 se retomó el tema, y con más fuerza todavía a principios de siglo (Patiño, Ruiz y Pitre, 2018). 


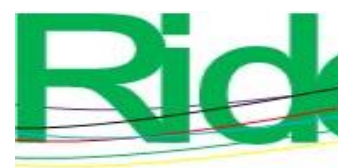

Revista Iberoamericana para la Investigación y el Desarrollo Educativo ISSN 2007 - 7467

moderno. Él ubica al emprendedor en el centro del escenario y desde allí le brinda un papel trascendental en el desarrollo económico. Otros como Knight (citado en Tarapuez y Botero, 2007) comenzaron a revelar los rasgos del emprendedor de forma imprecisa y le determinaron características como las siguientes: capacidad para tomar riesgos e incertidumbre, tenacidad, energía indomable, optimismo y fe, confianza en sí mismo, creatividad e imaginación, logro de beneficios efectivos, ser agente de cambio e innovación, creen que el dinero es su mayor motivación, poseen conocimiento del sector en el que van a instituir una empresa.

Hablar de emprendedores es discutir de diversas teorías y conceptos que se han ido creando a través del tiempo y de variadas investigaciones. Según Santander (2010), diversos autores concuerdan en que, antes de existir la presente figura del emprendedor o gerente de la era entrepreneur, existía el empresario tradicional.

Del mismo modo, la historia nos ha señalado que los emprendedores son agentes que originan la actividad económica y ayudan a generar ambientes de competencia por medio de la instauración de empresas o negocios (Morales et al., 2015).

Según Lozano y Cayetano (2011), en México y en el mundo la figura del emprendedor ha ido tomando una posición mítica en los últimos años que lo sitúa a la par de un héroe que lucha frente a las fuerzas del mercado con el fin de comenzar su aventura de negocio y ubicar una empresa. Autores como Santander (2010) aseveran que los emprendedores "se hacen" y, bajo este paradigma, el rol de la educación es trascendente, por lo que es preciso conocer e identificar las características y el comportamiento emprendedor para poder potencializarlos en los estudiantes de la universidad.

Un diagnóstico elaborado por el Instituto Nacional del Emprendedor (2016) soporta que México afronta un reto en materia de productividad. La evidencia teórica marca que la productividad total de los factores en la economía ha decrecido a una tasa promedio de $0.7 \%$, lo que desvirtúa conservar una economía en crecimiento. Por lo anterior, el emprendimiento es un tema que adquiere relevancia en las regiones y estados, especialmente donde se busca acelerar la economía.

En este orden de ideas, Hidalgo, Kamiya y Reyes (2014) exponen que la actividad emprendedora se ha consolidado como uno de los primordiales motores de desarrollo en todas las economías del mundo, especialmente por su función en la creación de empleo y expansión de sectores económicos y regiones emergentes. 


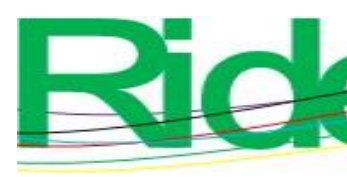

Revista Iberoamericana para la
Investigación y el Desarrollo Educativo
ISSN $2007-7467$

Uno de los aspectos significativos que debe considerar el emprendimiento es la generación de nuevas ideas, la innovación que admita una estabilidad en la economía general. De acuerdo con González (2012), la innovación se debe de manifestar en cualquier tipo de empresa que se crea. Es ineludible que se considere el fenómeno de emprendimiento tanto desde la perspectiva del individuo como desde las variables del medio que afectan dicha actividad.

Producto de la importancia que posee el emprendimiento en México, en el año 2016, el diputado Luis Fernando Antero Valle sometió a consideración la iniciativa de Ley General de Promoción e Impulso al Joven Emprendedor (Sistema de Información Legislativa de la Secretaría de Gobernación, 2016). En la mencionada propuesta, se atribuye, entre muchas otras razones, a prejuicios como la inexperiencia e inmadurez, así como a la educación que se limita a preparar al estudiante para un empleo y no para poseer las características que le permitan emprender un negocio propio. En la mencionada ley, se considera un financiamiento específico para la creación de nuevos negocios o empresas, asesoría e incubación de proyectos, hasta la consolidación de los mismos; todo lo anterior, impulsado por una comisión dictaminadora, integrada por miembros de instituciones como la Secretaría de Economía, Secretaría de Educación Pública (SEP), cámaras empresariales, entre otras. Paralelamente a este tipo de acciones, se debe promover una cultura de emprendimiento desde la educación en las escuelas, integrar los avances en ciencia, tecnología e innovación para que el emprendedor cuente con condiciones para desarrollar excelencias competitivas en su propia empresa. Aún más, es preciso que estos esfuerzos sean iniciados desde la educación básica, con el objetivo que, desde temprana edad, se introduzca a los futuros emprendedores la importancia de ser creadores de empleos y bienestar para toda la sociedad.

Ahora bien, Palomares y Chrisvert (2014) afirman que, en el espacio universitario, la toma de decisiones es más compleja, se amplían los espacios de reflexión, pero también de crítica y contrariedad con decisiones tomadas en otro plano jerárquico. Hernández y Arano (2015), por su parte, indican que las licenciaturas relacionadas con la administración o los negocios podrían ser más susceptibles a vincularse con en el proceso emprendedor. Las universidades buscan tener un entorno propicio para que sus estudiantes se introduzcan en planes y actividades que los trasladen a concretar sus ideas de negocios.

Cabe señalar que Caldera, León y Sánchez (2017) identifican el desempleo juvenil y subrayan que esta situación es extendida en países como México. Los datos de la Organización Internacional del Trabajo [OIT] (24 de agosto de 2016) muestran que la tasa 


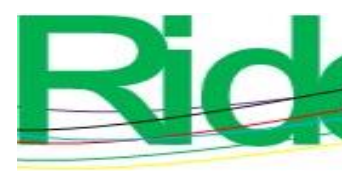

Revista Iberoamericana para la
Investigación y el Desarrollo Educativo
ISSN $2007-7467$

de desempleo juvenil mundial en 2015 fue de $12.9 \%$ y de $13.1 \%$ en 2016, y consideraron, en ese entonces, que persistiría en este nivel durante todo el 2017. Entre los aquejados, se encuentran jóvenes profesionistas con títulos universitarios. La información del Monitor Global de Emprendimiento (GEM, por sus siglas en inglés) para México muestra que en 2015 existía una tasa de actividad emprendedora prematura (TEA) de $21 \%$ (Lideres mexicanos, 2016). La TEA en la población joven (18 a 24 años) pasó de $12 \%$ en 2012 a 14.8 en 2014 (Durán, 2016). Podría aseverarse que la razón primordial por la que se decide emprender es porque se ha identificado una ocasión de negocio. La principal actividad en la que se emprende es en el comercio al por mayor y al por menor; posteriormente, se encuentran los servicios de manufactura. En cuanto a las políticas gubernamentales encaminadas al fomento de nuevos emprendimientos, México ocupa el lugar 15 de 62 economías que comprenden el GEM. En cuanto a la educación empresarial, nuestro país ocupa el lugar 45 de 62 economías que engloban el GEM (Durán, 2016).

Teniendo en cuenta lo anterior, Gibb (2011) sitúa las presiones que llevan a la sociedad empresarial a vincular el medio político con las iniciativas para emprender y hacer frente a las demandas de la capacidad global, así como la manera en que cambia y se adapta a las organizaciones de gobierno. Por otra parte, cuantiosos estudios discuten acerca de cómo las universidades deben incidir en el espíritu emprendedor de sus alumnos. Palomares y Chrisvert (2014) y Duarte y Ruiz (2009) también afirman que el medio educativo es el más conveniente y eficaz para transferir, participar y recrear la cultura del emprendimiento: en todos los niveles de la escuela se puede conformar esta cultura. Esto es percibido como un proceso pedagógico, en donde pueden crearse circunstancias laborales y la proyección de la riqueza en toda la población, todo encaminado y en función del desarrollo humano.

Es indispensable que las instituciones de educación superior promuevan en los alumnos una visión de desarrollo de negocios oportunos, con el objetivo de auxiliar, no solo a la reactivación económica, sino a la creación de fuentes de trabajo para una mejora en la calidad de vida de la población, y cumplir así con el deber de crear conocimiento y formar profesionistas sensibles a la realidad social (Hernández y Arano, 2015).

Se necesita seguir fomentando la creatividad del estudiante, mientras más temprano mejor. Se demanda un envolvimiento consciente de las autoridades estatales y municipales hacia la sociedad, además de que los empresarios comiencen a ver los servicios que les puede ofrecer la academia. 


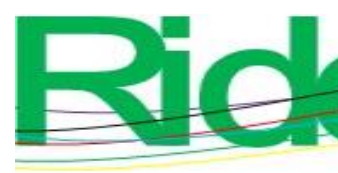

Revista Iberoamericana para la
Investigación y el Desarrollo Educativo
ISSN $2007-7467$

El propósito del presente estudio fue comparar los resultados del contexto internacional con el local sobre el emprendimiento social de base universitaria en estudiantes encuestados sobre el emprendimiento social.

\section{Materiales y método}

\section{Tipo de estudio}

El presente estudio tuvo un enfoque cuantitativo, con la ventaja de que los resultados de la muestra pueden ser ampliados a la población (Normas APA, s. f.). Además, los datos se obtuvieron a propósito de la investigación (primarios). Y es un estudio transversal, pues mide y obtiene datos en una sola ocasión, durante el semestre enero-junio de 2018 (Hernández, Fernández y Baptista, 2014).

\section{Población y muestra}

El presente estudio se llevó a cabo en la Unidad Académica de Contaduría y Administración de la Universidad Autónoma de Zacatecas, en la ciudad de Zacatecas, México. La población fue de 735 alumnos regulares de $8 .^{\circ}$ y $10 .^{\circ}$ semestre inscritos en la licenciatura escolarizada. Para calcular la muestra se utilizó la fórmula para poblaciones finitas, variable cualitativa (estimación de proporciones), con $95 \%$ de confianza $(z=1.96)$, un error máximo de $5 \%$ (0.05) y una variabilidad desconocida, por lo que $p=0.5$ y $q=1-p$, $q=0.5$. El tamaño de muestra resultó de 253 .

$$
n=\frac{N p q z^{2}}{e^{2}(N-1)+p q z^{2}} \quad n=\frac{(735)(.5)(.5)(1.96)^{2}}{(.05)^{2}(734)+(.5)(.5)(1.96)^{2}}=252.51 \cong 253
$$

Se lograron recabar 301 encuestas contestadas por los mencionados alumnos.

\section{Instrumento}

Para la presente investigación se utilizó un cuestionario estructurado diseñado en la Universidad de San Martín de Porres de Lima, Perú, el cual indagaba: información demográfica (género, edad, semestre cursado, información laboral); información de antecedentes emprendedores (si se tiene negocio familiar emprendedor y qué rol toma en este); "Intención de emprendimiento social" (disposición y probabilidad de emprender) (cinco ítems); "Percepción positiva del emprendimiento social” (visión social, innovación y 


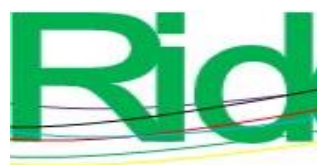

\section{Revista Iberoamericana para la Investigación y el Desarrollo Educativo ISSN 2007 - 7467}

sostenibilidad) (11 ítems); "Aprobación social del emprendimiento social" (opinión de familiares amigos y docentes al decidir emprender) (siete ítems); "Autoeficacia para desarrollar emprendimientos sociales" (percepción de los estudiantes acerca de su habilidad para desarrollar un proyecto de emprendimiento social), y "Soporte universitario para promover emprendimiento social" (acceso a recursos y programas de base universitaria para desarrollar emprendimiento social) (nueve ítems) (Giraldo y Vara, 2018).

\section{Procedimiento}

Se aplicó una encuesta cara a cara mediante el procedimiento de acudir a los salones de clase de los semestres ya especificados de la licenciatura escolarizada. Se les solicitó la información al tiempo que se recalcaba la confidencialidad de esta.

Tabla 1. Ficha técnica de la investigación

\begin{tabular}{|c|c|}
\hline Características & Encuesta \\
\hline Universo & 735 alumnos regulares de $8 .^{\circ}$ y $10 .^{\circ}$ semestre \\
\hline Ámbito de estudio & $\begin{array}{l}\text { Unidad Académica de Contaduría y } \\
\text { Administración de la Universidad } \\
\text { Autónoma de Zacatecas en México }\end{array}$ \\
\hline Unidad de análisis & $\begin{array}{l}\text { Alumno regular inscrito y cursando el } 8 .^{\circ} \mathrm{o} \\
10 .^{\circ} \text { semestre }\end{array}$ \\
\hline Método de recogida de información & Cuestionario estructurado \\
\hline Procedimiento de muestreo & Entrevista cara a cara \\
\hline Tamaño de muestra & 253 (301 aplicadas) \\
\hline Confianza y margen de error del muestreo & $\begin{array}{l}\text { Confianza de } 95 \% \text { y } 5 \% \text { de margen de } \\
\text { error, } p=q=0.5\end{array}$ \\
\hline Fecha de trabajo de campo & Enero-junio de 2018 \\
\hline
\end{tabular}

Nota: Para el cálculo de tamaño de muestra se recurrió a Landero y González (2007)

Fuente: Elaboración propia 


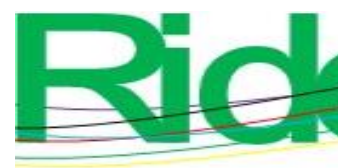
Revista Iberoamericana para la
Investigación y el Desarrollo Educativo
ISSN $2007-7467$

\section{Resultados}

Para evaluar los estadísticos descriptivos, se utilizó el paquete estadístico para las ciencias sociales SPSS versión 24. Entre los resultados, predomina que, del total de la muestra, $66.8 \%$ eran mujeres y el resto, $33.2 \%$, hombres. Además, $47.2 \%$ estaba cursando el $8 .^{\circ}$ semestre y el resto, $51.8 \%$, el $10 .^{\circ}$ semestre. De los entrevistados, $42.9 \%$ se dedica solo a estudiar; el resto, $57.1 \%$, estudia y trabaja. Entre estos últimos, $32.2 \%$ manifestó ganar entre 100 y 200 dólares americanos al mes, con un promedio de 14.89 meses de experiencia laboral. Asimismo, $26.2 \%$ de los entrevistados manifestó que su familia cuenta con algún tipo de negocio. De estos, solo cuatro alumnos, correspondiente a $1.3 \%$ de la muestra, lideran el mencionado negocio. Aún más: del total de estos negocios, $10.6 \%$ fueron considerados como de emprendimiento social, sin embargo, solo dos estudiantes, esto es, $0.7 \%$ del total de encuestados, participa como líder del emprendimiento social.

Respecto al modelo de emprendimiento social de base universitaria, se utilizó el SmartPLS versión 3.2.2 (Ringle, Wende y Becker, 2015). Se contó con más del tamaño mínimo de muestra requerido por una ecuación estructural (Hair, Black, Babin y Anderson, 2010).

\section{Evaluación del modelo de medida}

De acuerdo a Chin (2010), el primer paso para un análisis de ecuaciones estructurales no basado en covarianza es el modelo de medida o externo en el que se evalúa la validez convergente: cargas de los ítems y varianza extraída (AVE), y la fiabilidad: alfa de Cronbach y fiabilidad compuesta. Por lo que se procedió al análisis del modelo de medida o externo (Hair, Hult, Ringle y Sarstedt, 2007) del modelo original, el cual fue evaluado eliminando de este los ítems cuya carga externa no fuera de por menos 0.40 , esto dado que al menos $50 \%$ de la varianza de cada indicador debe explicarse por el constructo subyacente (Sarstedt, Ringle y Hair, 2017). El resultado se muestra en la tabla 2. 
Tabla 2. Evaluación del modelo de medida: fiabilidad y validez convergente $(n=301)$

\begin{tabular}{|c|c|c|c|c|c|}
\hline \multirow{2}{*}{ 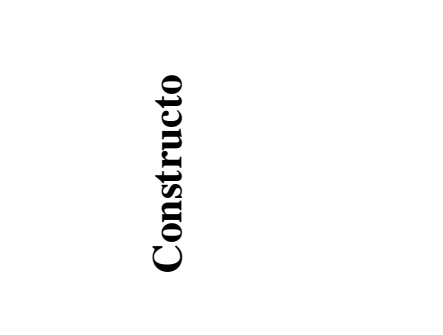 } & \multirow[t]{2}{*}{ 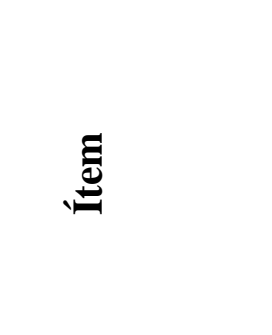 } & \multicolumn{2}{|c|}{ 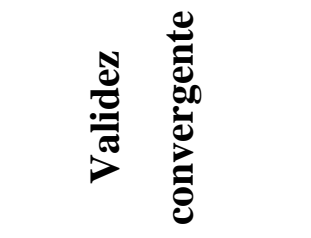 } & \multirow{2}{*}{ 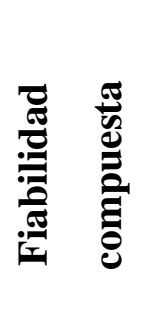 } & \multirow{2}{*}{ 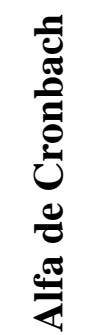 } \\
\hline & & Cargas & $\mathbf{A V E}$ & & \\
\hline \multirow[t]{5}{*}{ Aprobación social } & NSProfesores1 & 0.889 & 0.675 & 0.912 & 0.878 \\
\hline & NSProfesores2 & 0.858 & & & \\
\hline & NSProfesores3 & 0.827 & & & \\
\hline & NSAmigos1 & 0.796 & & & \\
\hline & NSFamilia1 & 0.727 & & & \\
\hline \multirow[t]{4}{*}{ Autoeficacia } & Autf1 & 0.792 & .648 & 0.88 & 0.818 \\
\hline & Autf2 & 0.754 & & & \\
\hline & Autf3 & 0.847 & & & \\
\hline & Autf4 & 0.824 & & & \\
\hline \multirow[t]{5}{*}{ Intención emprendedora } & Int1 & 0.856 & 0.682 & 0.915 & 0.884 \\
\hline & Int2 & 0.856 & & & \\
\hline & Int3 & 0.814 & & & \\
\hline & Int4 & 0.799 & & & \\
\hline & Int5 & 0.803 & & & \\
\hline \multirow{4}{*}{$\begin{array}{l}\text { Percepción positiva del } \\
\text { emprendimiento social }\end{array}$} & PercINN4 & 0.805 & 0.627 & 0.87 & 0.801 \\
\hline & PercINN5 & 0.82 & & & \\
\hline & PercSS3 & 0.743 & & & \\
\hline & PercVS3 & 0.798 & & & \\
\hline \multirow{5}{*}{$\begin{array}{l}\text { Soporte institucional del } \\
\text { emprendimiento social }\end{array}$} & Eco1 & 0.86 & 0.714 & .957 & 0.95 \\
\hline & Eco2 & 0.815 & & & \\
\hline & Eco3 & 0.851 & & & \\
\hline & Eco4 & 0.862 & & & \\
\hline & Eco5 & 0.834 & & & \\
\hline
\end{tabular}



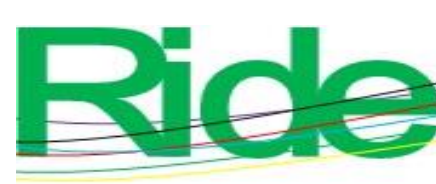

Revista Iberoamericana para la Investigación y el Desarrollo Educativo ISSN 2007 - 7467

Tabla 3. Evaluación del modelo de medida: validez discriminante $(n=301)$

\begin{tabular}{|c|c|c|c|c|c|c|}
\hline & 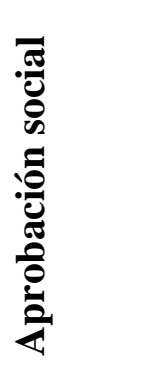 & 吾 & 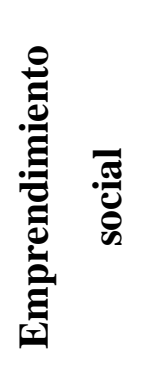 & 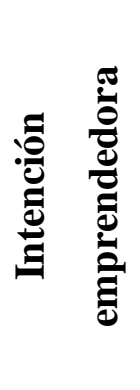 & 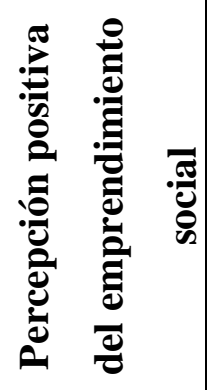 & 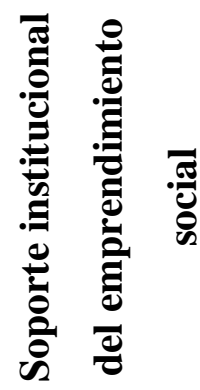 \\
\hline Aprobación social & 0.821 & & & & & \\
\hline Autoeficacia & 0.555 & 0.805 & & & & \\
\hline $\begin{array}{c}\text { Emprendimiento } \\
\text { social }\end{array}$ & -0.015 & 0.022 & 1 & & & \\
\hline $\begin{array}{c}\text { Intención } \\
\text { emprendedora }\end{array}$ & 0.678 & 0.731 & -0.004 & 0.826 & & \\
\hline $\begin{array}{c}\text { Percepción positiva } \\
\text { del emprendimiento } \\
\text { social }\end{array}$ & 0.411 & 0.479 & 0.046 & 0.358 & 0.792 & \\
\hline $\begin{array}{c}\text { Soporte } \\
\text { institucional del } \\
\text { emprendimiento } \\
\text { social }\end{array}$ & 0.295 & 0.326 & 0.104 & 0.299 & 0.466 & 0.845 \\
\hline
\end{tabular}

Fuente: Elaboración propia

En la tabla anterior se observa que la raíz cuadrada de AVE en la diagonal principal es mayor que las correlaciones de la variable latente fuera de ella, y se comprueba la validez discriminante. El valor de uno en el constructo "Emprendimiento social" se debe a que es un indicador de un solo ítem, los cuales son usados para medir conceptos como satisfacción o intención (Hair et al., 2007) y siempre presentan como resultado ese valor para este tipo de análisis. 


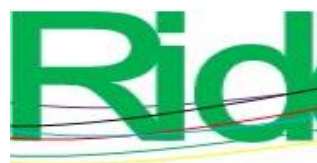

Las cargas cruzadas, siguiendo a Fornell y Larker (1981), son una forma de detectar problemas de validez discriminante al comprobar que los ítems de un constructo tengan correlaciones más altas con su constructo que con otros.

Tabla 4. Cargas cruzadas

\begin{tabular}{|c|c|c|c|c|c|c|}
\hline & 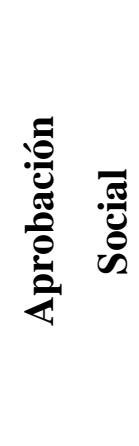 & 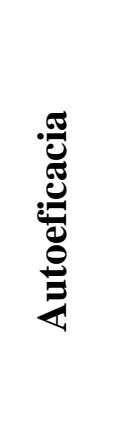 & 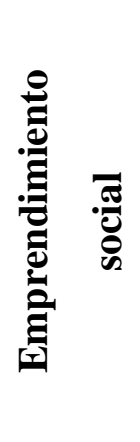 & 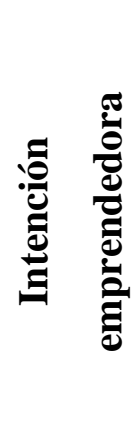 & 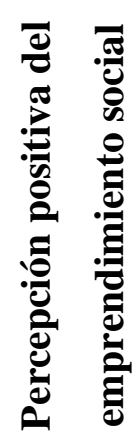 & 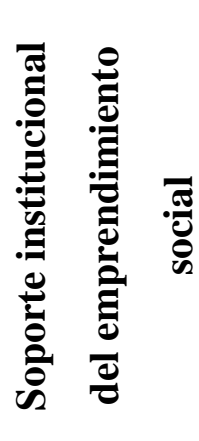 \\
\hline Autf1 & 0.475 & 0.792 & 0.039 & 0.577 & 0.39 & 0.231 \\
\hline Autf2 & 0.315 & 0.754 & 0.08 & 0.424 & 0.508 & 0.419 \\
\hline Autf3 & 0.458 & 0.847 & 0.011 & 0.6 & 0.326 & 0.282 \\
\hline Autf4 & 0.524 & 0.824 & -0.046 & 0.728 & 0.332 & 0.142 \\
\hline Eco1 & 0.265 & 0.285 & 0.051 & 0.201 & 0.442 & 0.86 \\
\hline Eco2 & 0.359 & 0.347 & 0.05 & 0.391 & 0.39 & 0.815 \\
\hline Eco3 & 0.269 & 0.292 & 0.053 & 0.274 & 0.387 & 0.851 \\
\hline Eco4 & 0.224 & 0.277 & 0.139 & 0.283 & 0.38 & 0.862 \\
\hline Eco5 & 0.248 & 0.274 & 0.096 & 0.256 & 0.384 & 0.834 \\
\hline Eco6 & 0.251 & 0.296 & 0.087 & 0.249 & 0.391 & 0.855 \\
\hline Eco7 & 0.253 & 0.268 & 0.087 & 0.23 & 0.39 & 0.82 \\
\hline Eco8 & 0.219 & 0.207 & 0.121 & 0.204 & 0.411 & 0.859 \\
\hline Eco9 & 0.106 & 0.202 & 0.121 & 0.135 & 0.359 & 0.847 \\
\hline Int1 & 0.539 & 0.667 & 0.009 & 0.856 & 0.319 & 0.239 \\
\hline Int2 & 0.619 & 0.65 & -0.029 & 0.856 & 0.272 & 0.237 \\
\hline Int3 & 0.538 & 0.585 & 0.02 & 0.814 & 0.288 & 0.259 \\
\hline Int4 & 0.471 & 0.529 & 0.048 & 0.799 & 0.259 & 0.354 \\
\hline Int5 & 0.62 & 0.574 & -0.056 & 0.803 & 0.337 & 0.163 \\
\hline NSAmig1 & 0.796 & 0.408 & 0 & 0.552 & 0.299 & 0.163 \\
\hline NSFamil1 & 0.727 & 0.448 & -0.033 & 0.416 & 0.473 & 0.254 \\
\hline
\end{tabular}




\begin{tabular}{|c|c|c|c|c|c|c|}
\hline NSProfe1 & 0.889 & 0.421 & -0.028 & 0.578 & 0.344 & 0.187 \\
\hline NSProfe2 & 0.858 & 0.484 & 0.013 & 0.62 & 0.32 & 0.334 \\
\hline NSProfe3 & 0.827 & 0.514 & -0.016 & 0.604 & 0.261 & 0.26 \\
\hline PercINN4 & 0.32 & 0.402 & 0.067 & 0.279 & 0.805 & 0.396 \\
\hline PercINN5 & 0.333 & 0.377 & 0.033 & 0.27 & 0.82 & 0.375 \\
\hline PercSS3 & 0.298 & 0.35 & 0.041 & 0.303 & 0.743 & 0.372 \\
\hline PercVS3 & 0.349 & 0.384 & 0.003 & 0.282 & 0.798 & 0.333 \\
\hline
\end{tabular}

Fuente: Elaboración propia

En los resultados de la tabla 4 no se encuentran problemas de validez discriminante. De acuerdo con la prueba de cargas cruzadas, se observó que los indicadores cargan más en sus constructos asociados que en otros constructos. Sin embargo, los mencionados criterios de Fornell y Larker (1981) y las cargas cruzadas son insuficientes para detectar problemas de validez discriminante; un novedoso método para evaluar la validez discriminante es el llamado Heterotrait-Monotrait Ratio (HTMT), que consiste en verificar que las correlaciones entre ítems del mismo constructo deben ser mayores que las correlaciones de ítems de diferentes constructos. 
Tabla 5. HTMT

\begin{tabular}{|c|c|c|c|c|c|c|}
\hline & 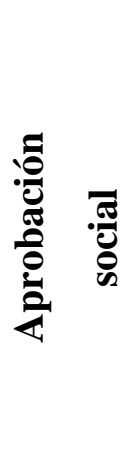 & 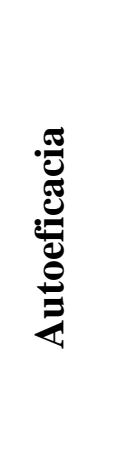 & 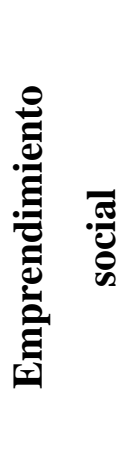 & 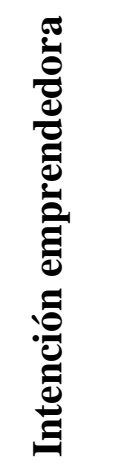 & 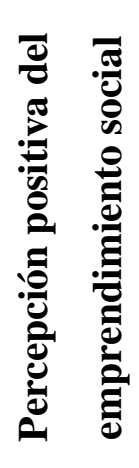 & 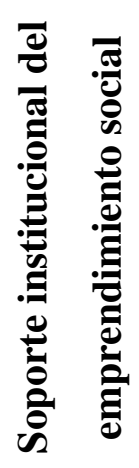 \\
\hline $\begin{array}{l}\text { Aprobación } \\
\text { Social }\end{array}$ & & & & & & \\
\hline Autoeficacia & 0.649 & & & & & \\
\hline $\begin{array}{l}\text { Emprendimiento } \\
\text { Social }\end{array}$ & 0.024 & 0.06 & & & & \\
\hline Intención emprendedora & 0.763 & 0.847 & 0.042 & & & \\
\hline $\begin{array}{l}\text { Percepción positiva del } \\
\text { emprendimiento social }\end{array}$ & 0.494 & 0.597 & 0.051 & 0.425 & & \\
\hline $\begin{array}{l}\text { Soporte institucional del } \\
\text { emprendimiento social }\end{array}$ & 0.313 & 0.374 & 0.109 & 0.325 & 0.533 & \\
\hline
\end{tabular}

Fuente: Elaboración propia

En la tabla 5 se verifican los valores del HTMT, los cuales deben ser preferentemente menores a 0.85 , o al menos 0.90 (Henseler, Ringle y Sarstedt, 2015).

\section{Evaluación del modelo: resultados del modelo estructural}

De acuerdo con Chin (2010), una vez que se ha establecido que el modelo de medida es idóneo, el siguiente paso es proporcionar evidencia para apoyar el modelo teórico, principalmente el poder predictivo con los valores del coeficiente de determinación $R^{2}$ y la importancia de las estimaciones de ruta.

Para el modelo estructural, Hair et al. (2007) recomiendan evaluar los siguientes puntos:

1) Colinealidad entre los constructos;

2) Significancia y relevancia de los coeficientes de ruta;

3) Relevancia predictiva $\left(R^{2}, f^{2}, Q^{2}, q^{2}, P L S\right.$ predict $)$, y

4) Bondad de ajuste. 

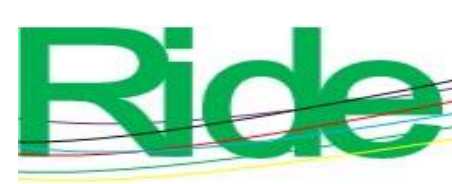

Revista Iberoamericana para la Investigación y el Desarrollo Educativo

ISSN 2007 - 7467

Como se mencionó anteriormente, para la presente investigación se utilizó la técnica de mínimos cuadrados parciales, ya que en simulaciones se ha encontrado que es un método bastante robusto para deficiencias como la colinealidad (Cassel, Hackl y Westlund, 1999). Para evaluarla, se utilizó el factor de inflación de varianza (VIF).

Tabla 6. VIF

\begin{tabular}{|c|c|c|c|c|c|c|c|}
\hline & AP & A & ES & IE & PPES & \multicolumn{2}{|c|}{ SIES } \\
\hline AP & & & 1.976 & 1.505 & 1.096 & & \\
\hline $\mathbf{A}$ & & & 2.434 & 1.623 & & & \\
\hline ES & & & & & & & \\
\hline IE & & & 2.826 & & & & \\
\hline PPES & & 1.278 & 1.566 & 1.35 & & & \\
\hline SIES & 1 & 1.278 & 1.315 & & 1.096 & & \\
\hline
\end{tabular}

$A P=$ Aprobación social, $A=$ Autoeficacia, $E S=$ Emprendimiento social, $I E=$ Intención emprendedora, $P P E S$ $=$ Percepción positiva del emprendimiento social y SIES $=$ Soporte institucional del emprendimiento social.

Fuente: Elaboración propia

Al evaluar el VIF, como se muestra en la tabla 6, el cual debe ser menor a cinco, no se encontró ningún problema de colinealidad entre los constructos.

Los coeficientes de ruta varían entre -1 y 1 . Valores absolutos más altos denotan relaciones predictivas más fuertes entre los constructos, teniendo efectos directos: relación con una sola flecha uniendo constructos; indirectos: secuencia de relaciones que involucra por lo menos un constructo interviniente, y un efecto total: suma de efectos directos e indirectos (Hair et al., 2007). 
Tabla 7. Coeficientes de ruta (path)

\begin{tabular}{|l|c|c|c|c|c|}
\hline & & & & & \\
\hline $\begin{array}{l}\text { Aprobación social } \\
\text { Emprendimiento social }\end{array}$ & -0.048 & -0.051 & 0.081 & 0.591 & 0.555 \\
\hline $\begin{array}{l}\text { Aprobación social } \\
\text { Intención emprendedora }\end{array}$ & 0.408 & 0.408 & 0.046 & 8.845 & 0 \\
\hline $\begin{array}{l}\text { Aprobación social } \\
\text { Percepción positiva del } \\
\text { emprendimiento social }\end{array}$ & 0.299 & 0.296 & 0.074 & 4.024 & 0 \\
\hline $\begin{array}{l}\text { Autoeficacia } \\
\text { Emprendimiento social }\end{array}$ & 0.031 & 0.031 & 0.084 & 0.364 & 0.716 \\
\hline $\begin{array}{l}\text { Autoeficacia } \\
\text { Intención emprendedora }\end{array}$ & 0.536 & 0.539 & 0.052 & 10.253 & 0 \\
\hline $\begin{array}{l}\text { Intención emprendedora } \\
\text { Emprendimiento social }\end{array}$ & -0.031 & -0.023 & 0.091 & 0.344 & 0.731 \\
\hline $\begin{array}{l}\text { Percepción positiva del } \\
\text { emprendimiento social } \\
\text { Autoeficacia }\end{array}$ & 0.417 & 0.412 & 0.072 & 5.804 & 0 \\
\hline $\begin{array}{l}\text { Percepción positiva del } \\
\text { emprendimiento social } \\
\text { Emprendimiento social }\end{array}$ & 0.01 & 0.01 & 0.071 & 0.137 & 0.891 \\
\hline $\begin{array}{l}\text { Percepción positiva del } \\
\text { emprendimiento social } \\
\text { Intención emprendedora }\end{array}$ & -0.067 & -0.07 & 0.046 & 1.434 & 0.152 \\
\hline $\begin{array}{l}\text { Soporte institucional del } \\
\text { emprendimiento social } \\
\text { Aprobación social }\end{array}$ & 0.295 & 0.294 & 0.061 & 4.816 & 0 \\
\hline $\begin{array}{l}\text { Soporte institucional del } \\
\text { emprendimiento social }\end{array}$ & 0.131 & 0.135 & 0.068 & 1.943 & 0.053 \\
\hline
\end{tabular}




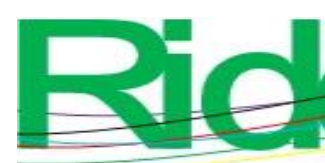

\begin{tabular}{|l|c|c|c|c|c|}
\hline Autoeficacia & & & & \\
\hline $\begin{array}{l}\text { Soporte institucional del } \\
\text { emprendimiento social } \\
\text { Emprendimiento social }\end{array}$ & 0.113 & 0.114 & 0.049 & 2.289 & 0.022 \\
\hline $\begin{array}{l}\text { Soporte institucional del } \\
\text { emprendimiento social } \\
\text { Percepción positiva del } \\
\text { emprendimiento social }\end{array}$ & 0.378 & 0.381 & 0.059 & 6.389 & 0 \\
\hline
\end{tabular}

Fuente: Elaboración propia

De la tabla 7, en la que se observan los coeficientes de ruta, se desprende que "Aprobación social" está fuertemente relacionada con "Intención emprendedora" (0.408) y con "Percepción positiva del emprendimiento social" (0.299), mientras que "Soporte institucional" lo está con "Aprobación social" (0.295) y con "Percepción positiva del emprendimiento social" (0.378). "Autoeficacia" es el más fuerte conductor de "Intención emprendedora" (0.536), mientras que "Percepción positiva del emprendimiento social" lo es de "Autoeficacia" (0.417).

Los efectos totales, suma de los directos e indirectos, indican la fuerza del efecto sobre una variable objetivo, en este caso la intención emprendedora. 
Tabla 8. Efectos totales

\begin{tabular}{|c|c|c|c|c|c|}
\hline & 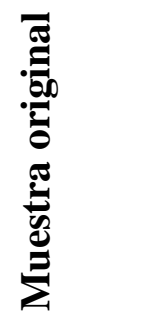 & 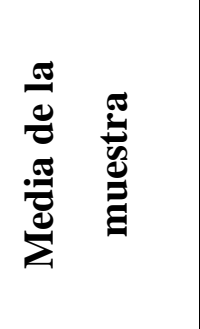 & 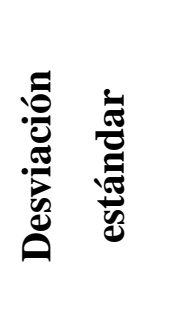 & 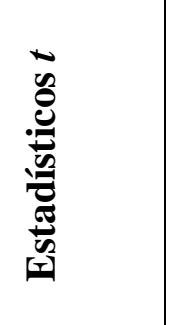 & 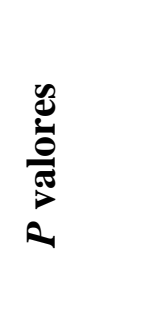 \\
\hline $\begin{array}{l}\text { Aprobación social } \\
\text {-> Autoeficacia }\end{array}$ & 0.125 & 0.125 & 0.047 & 2.651 & 0.008 \\
\hline $\begin{array}{l}\text { Aprobación social } \\
\text {-> } \\
\text { Emprendimiento } \\
\text { social }\end{array}$ & -0.055 & -0.056 & 0.064 & 0.872 & 0.384 \\
\hline $\begin{array}{l}\text { Aprobación social } \\
\text {-> Intención } \\
\text { emprendedora }\end{array}$ & 0.455 & 0.456 & 0.046 & 9.96 & 0 \\
\hline $\begin{array}{l}\text { Aprobación social } \\
\text {-> Percepción } \\
\text { positiva del } \\
\text { emprendimiento } \\
\text { social }\end{array}$ & 0.299 & 0.296 & 0.074 & 4.024 & 0 \\
\hline $\begin{array}{l}\text { Autoeficacia -> } \\
\text { Emprendimiento } \\
\text { social }\end{array}$ & 0.014 & 0.019 & 0.079 & 0.174 & 0.862 \\
\hline $\begin{array}{l}\text { Autoeficacia -> } \\
\text { Intención } \\
\text { emprendedora }\end{array}$ & 0.536 & 0.539 & 0.052 & 10.253 & 0 \\
\hline \begin{tabular}{|l|} 
Intención \\
emprendedora -> \\
Emprendimiento \\
social
\end{tabular} & -0.031 & -0.023 & 0.091 & 0.344 & 0.731 \\
\hline $\begin{array}{l}\text { Percepción } \\
\text { positiva del }\end{array}$ & 0.417 & 0.412 & 0.072 & 5.804 & 0 \\
\hline
\end{tabular}




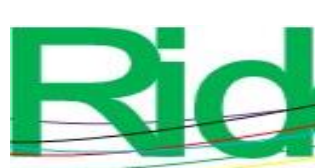

Revista Iberoamericana para la Investigación y el Desarrollo Educativo ISSN 2007 - 7467

\begin{tabular}{|c|c|c|c|c|c|}
\hline $\begin{array}{l}\text { emprendimiento } \\
\text { social -> } \\
\text { Autoeficacia }\end{array}$ & & & & & \\
\hline $\begin{array}{l}\text { Percepción } \\
\text { positiva del } \\
\text { emprendimiento } \\
\text { social -> } \\
\text { Emprendimiento } \\
\text { social }\end{array}$ & 0.018 & 0.02 & 0.067 & 0.26 & 0.795 \\
\hline $\begin{array}{l}\text { Percepción } \\
\text { positiva del } \\
\text { emprendimiento } \\
\text { social -> Intención } \\
\text { emprendedora }\end{array}$ & 0.157 & 0.152 & 0.063 & 2.502 & 0.013 \\
\hline $\begin{array}{l}\text { Soporte } \\
\text { institucional del } \\
\text { emprendimiento } \\
\text { social -> } \\
\text { Aprobación social }\end{array}$ & 0.295 & 0.294 & 0.061 & 4.816 & 0 \\
\hline $\begin{array}{l}\text { Soporte } \\
\text { institucional del } \\
\text { emprendimiento } \\
\text { social -> } \\
\text { Autoeficacia }\end{array}$ & 0.326 & 0.328 & 0.067 & 4.846 & 0 \\
\hline $\begin{array}{l}\text { Soporte } \\
\text { institucional del } \\
\text { emprendimiento } \\
\text { social -> } \\
\text { Emprendimiento } \\
\text { social }\end{array}$ & 0.105 & 0.106 & 0.051 & 2.07 & 0.039 \\
\hline $\begin{array}{l}\text { Soporte } \\
\text { institucional del }\end{array}$ & 0.264 & 0.265 & 0.058 & 4.582 & 0 \\
\hline
\end{tabular}




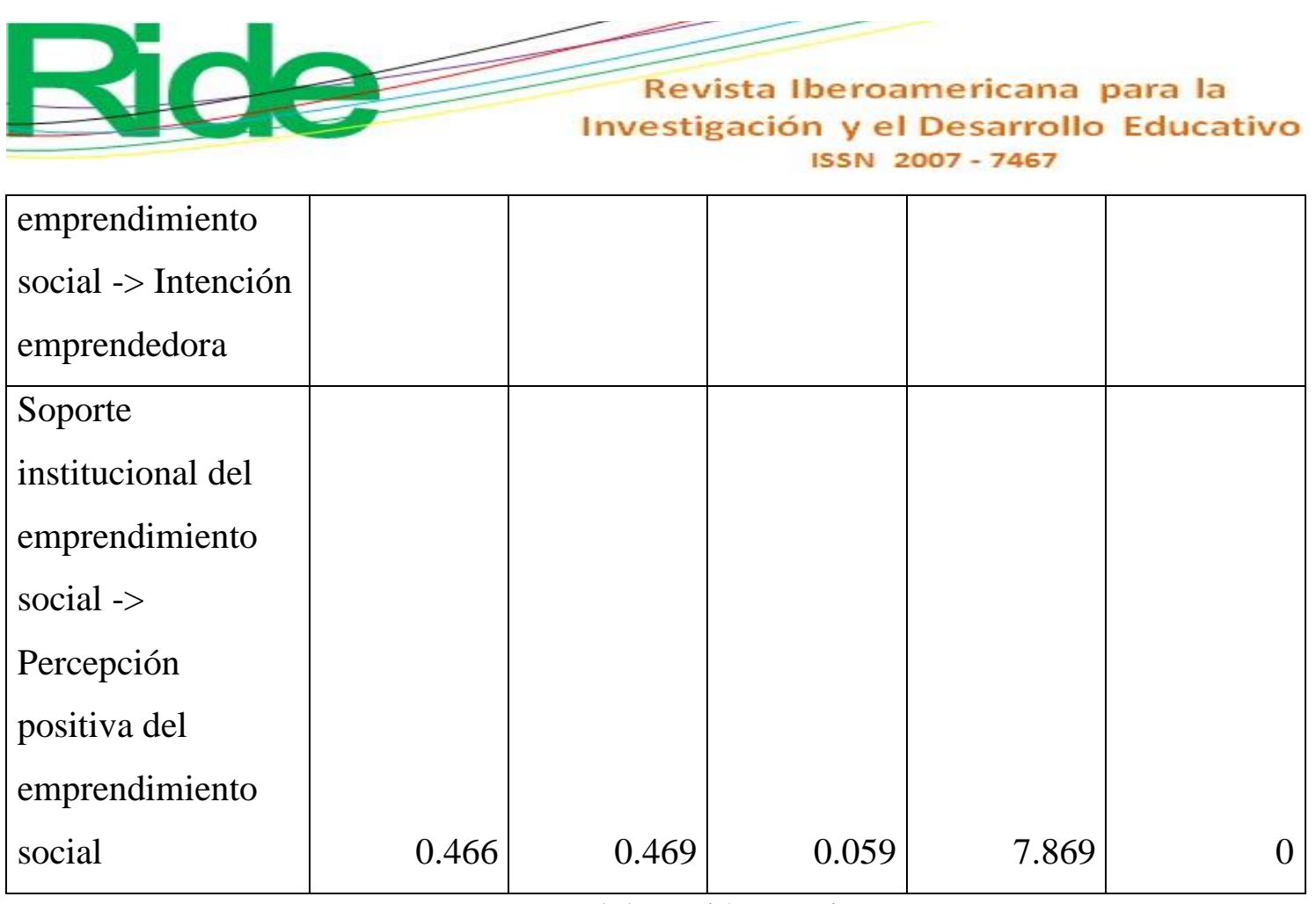

Fuente: Elaboración propia

De la tabla 8 se deduce que "Autoeficacia" tiene el más fuerte efecto total sobre la variable objetivo, "Intención emprendedora", seguido por "Aprobación social”, "Soporte institucional" y "Percepción positiva del emprendimiento social".

La relevancia predictiva, con el coeficiente de determinación $R^{2}$ y el tamaño del efecto $f^{2}$, son la predicción dentro de la muestra, el poder explicativo; el coeficiente de determinación $R^{2}$ representa la cantidad de varianza en los constructos endógenos explicada por todos los constructos exógenos vinculados a él, oscila entre cero y uno, donde los niveles más altos indican mayor precisión predictiva (Hair et al., 2007).

Tabla 9. Coeficiente de determinación $R^{2}$

\begin{tabular}{|l|c|c|}
\hline & $\boldsymbol{R}$ cuadrado & $\boldsymbol{R}$ cuadrado ajustada \\
\hline Aprobación social & 0.087 & 0.084 \\
\hline Autoeficacia & 0.243 & 0.238 \\
\hline Emprendimiento social & 0.014 & -0.003 \\
\hline Intención emprendedora & 0.645 & 0.641 \\
\hline Percepción positiva del emprendimiento social & 0.299 & 0.295 \\
\hline
\end{tabular}

Fuente: Elaboración propia

Como se puede observar en la tabla 9, el valor de "Intención emprendedora" tiene el coeficiente de determinación más alto, incluso utilizando la $R^{2}$ ajustada, que elimina el problema del aumento de $R^{2}$ al incluir constructos predictores adicionales: representa la 

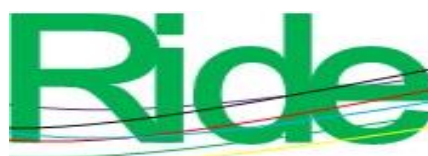

Revista Iberoamericana para la Investigación y el Desarrollo Educativo ISSN $2007-7467$

cantidad de varianza explicada por todos los constructos vinculados a él, de manera directa e indirecta.

El tamaño del efecto $f^{2}$ evalúa con qué fuerza un constructo exógeno contribuye a explicar un cierto constructo endógeno en términos de $R^{2}$.

Tabla 10. Tamaño del efecto $f^{2}$

\begin{tabular}{|c|c|c|c|c|c|c|c|}
\hline & 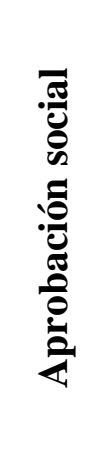 & 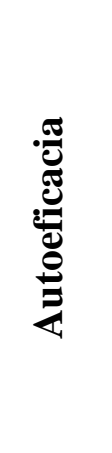 & 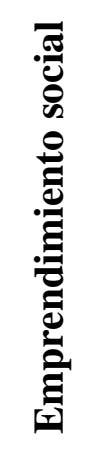 & 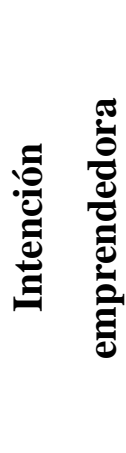 & 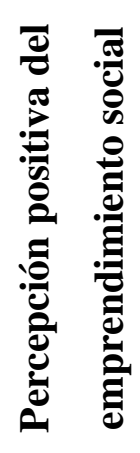 & 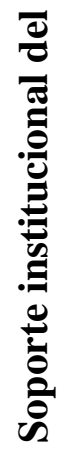 & 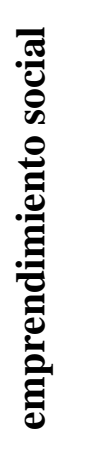 \\
\hline $\begin{array}{c}\text { Aprobación } \\
\text { social }\end{array}$ & & & 0.001 & 0.311 & 0.117 & & \\
\hline Autoeficacia & & & 0 & 0.498 & & & \\
\hline \multicolumn{8}{|l|}{$\begin{array}{c}\text { Emprendimiento } \\
\text { social }\end{array}$} \\
\hline $\begin{array}{c}\text { Intención } \\
\text { emprendedora }\end{array}$ & & & 0 & & & & \\
\hline $\begin{array}{c}\text { Percepción } \\
\text { positiva del ES }\end{array}$ & & 0.18 & 0 & 0.009 & & & \\
\hline $\begin{array}{c}\text { Soporte } \\
\text { institucional ES }\end{array}$ & 0.096 & 0.018 & 0.01 & & 0.186 & & \\
\hline
\end{tabular}

Fuente: Elaboración propia

En el presente estudio, como se puede apreciar en la tabla 10, "Autoeficacia" (exógeno) tiene un efecto fuerte $\left(f^{2}>.35\right)$ sobre "Intención emprendedora" (endógeno). "Percepción positiva del emprendimiento social", "Aprobación social" y "Soporte institucional" tienen un efecto moderado $\left(15 \geq f^{2}<.35\right)$ sobre "Autoeficacia", "Intención emprendedora" y "Percepción positiva del emprendimiento social", respectivamente.

Para la relevancia predictiva $Q^{2}$, se utiliza el procedimiento llamado blindfolding, el cual consiste en un procedimiento iterativo en el que se omiten diferentes partes de la matriz 

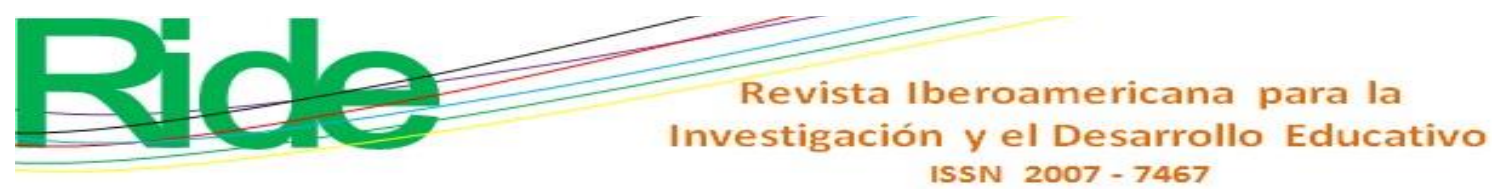

hasta que cada punto de los datos se haya omitido y predicho. El error de predicción es usado como indicador de relevancia predictiva (Hair et al., 2007), lo que permite evaluar la relevancia predictiva de cada constructo exógeno para un determinado constructo endógeno. Se considera una medida de predicción fuera de la muestra al permanecer esta casi intacta en su cálculo (Sarstedt et al., 2017).

Tabla 11. Relevancia predictiva $Q^{2}$

\begin{tabular}{|l|c|c|c|}
\hline & SSO & SSE & $\mathbf{Q}^{\mathbf{2}}$ (= 1-SSE/SSO) \\
\hline Aprobación social & 1505 & 1421.945 & 0.055 \\
\hline Autoeficacia & 1204 & 1019.095 & 0.154 \\
\hline Emprendimiento social & 301 & 305.964 & -0.016 \\
\hline Intención emprendedora & 1505 & 857.994 & 0.43 \\
\hline $\begin{array}{l}\text { Percepción positiva del emprendimiento } \\
\text { social }\end{array}$ & 1204 & 989.548 & 0.178 \\
\hline $\begin{array}{l}\text { Soporte institucional del emprendimiento } \\
\text { social }\end{array}$ & 2709 & 2709 & \\
\hline
\end{tabular}

Fuente: Elaboración propia

En la tabla 11 se observa cómo "Intención emprendedora" tiene un poder predictivo fuerte $\left(Q^{2}>0.35\right)$, mientras que "Autoeficacia y "Percepción positiva del emprendimiento social" tienen poder predictivo moderado $\left(0.15 \leq Q^{2} \leq 0.35\right)$.

\section{Bondad de ajuste}

De acuerdo con Tenenhaus, Esposito, Chatelin y Lauro (2005), a diferencia de los modelos basados en covarianza, usando PLS no es posible separar modelos válidos de no válidos. Sin embargo, según Lohmöller (1989), se puede medir el grado en que correlacionan los residuos del modelo externo utilizando la covarianza residual cuadrática media (RMStheta), la cual debe estar entre los valores de $\leq 0.12$ - 0.14 (Henseler, 2013). Para la presente investigación, se obtuvo un valor de RMStheta $=0.133$, lo cual, al estar dentro de los parámetros, se obtiene la bondad de ajuste del modelo. 


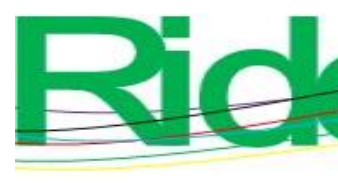

Revista Iberoamericana para la Investigación y el Desarrollo Educativo ISSN 2007-7467

\section{Discusión}

Ser emprendedor significa tomar riesgos, usar la inteligencia, trabajar e innovar. Existen riesgos que deben ser resueltos por los propios emprendedores (Morales et al., 2015). De acuerdo con Santander (2010), los emprendedores se hacen. Y Palomares y Chrisvert (2014), así como Duarte y Ruiz (2009), señalan a la educación como el medio más conveniente para transferir, participar y recrear la cultura del emprendimiento. Mientras que Hernández y Arano (2015) precisan cómo la educación relacionada con la administración y los negocios es la más propicia para el desarrollo del emprendimiento. Se trata de una alternativa para solventar el desempleo juvenil (Caldera et al., 2017). Puesto que, de acuerdo con el Instituto Nacional del Emprendedor (2016), cada año la economía mexicana decrementa $0.7 \%$. Y el GEM halló que este, el desempleo, se da en $12.7 \%$ entre jóvenes de 18 a 24 años.

El propósito principal de la presente investigación consistió en evaluar los modelos (original y el particular del contexto investigado), dado que el modelado de PLS puede servir para investigación tanto explicativa como predictiva (Cepeda, Henseler, Ringle y Roldán, 2016). Después de evaluar el modelo de medida o externo, así como el estructural o interno, se obtuvo un cambio significativo del modelo original del estudio que fue elaborado en 26 universidades de ocho países. Así, dos de los constructos difieren del original:

- "Aprobación social": con dos ítems menos, que se refieren a considerar importante la opinión de la familia, así como la de los amigos, lo que indica que, a diferencia del estudio original, aunque contestaron que sería importante que estén de acuerdo con ellos, la percepción de la gente cercana al estudiante no influye de manera significativa en su decisión o intención de emprender

- "Percepción positiva del emprendimiento social": de los 11 ítems, solo conservó cuatro posterior a la evaluación de cargas que no llegaron al valor mínimo de 0.4. De lo anterior se concluye que el alumno de la Unidad Académica de Contaduría y Administración de la Universidad Autónoma de Zacatecas no percibe estar enfocado en problemas sociales ni tener un fuerte compromiso social, no ven los riesgos como oportunidades, no advierten mejorar la vida a largo plazo o preservar el medio ambiente; sin embargo, observan tener facilidad para identificar necesidades sociales, crear mayor valor social que los emprendedores clásicos al poseer ventajas a través de productos y servicios innovadores y con esto proveer soluciones a necesidades sociales desatendidas. Por lo que el 

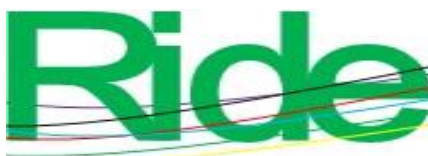

Revista Iberoamericana para la

Investigación y el Desarrollo Educativo

ISSN 2007 - 7467

modelo cambió del contexto internacional, como se aprecia en la figura 1, al modelo del contexto de la presente investigación, como se muestra en la figura 2.

Figura 1. Modelo internacional

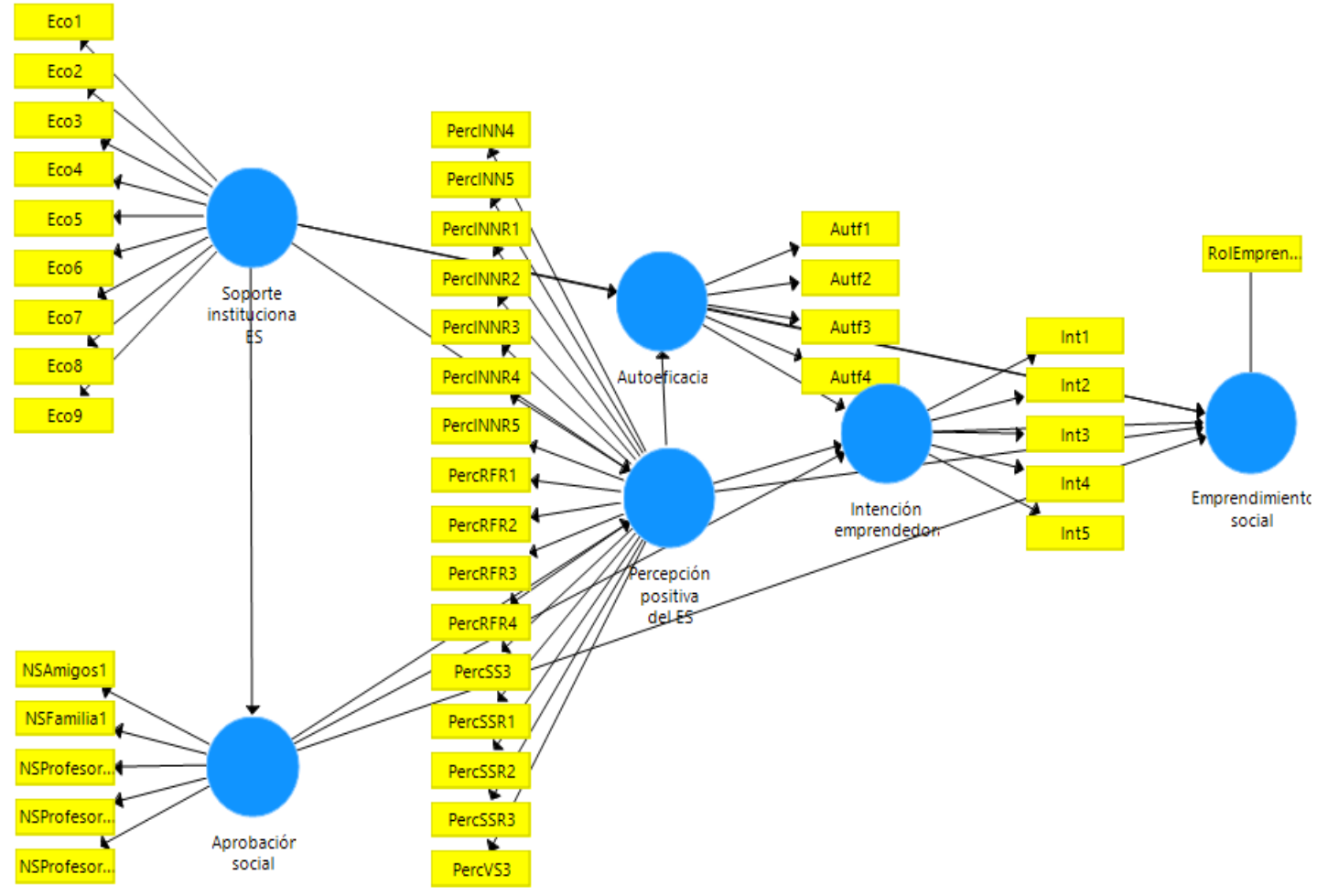

Fuente: Giraldo y Vara (2018)

Figura 2. Modelo local

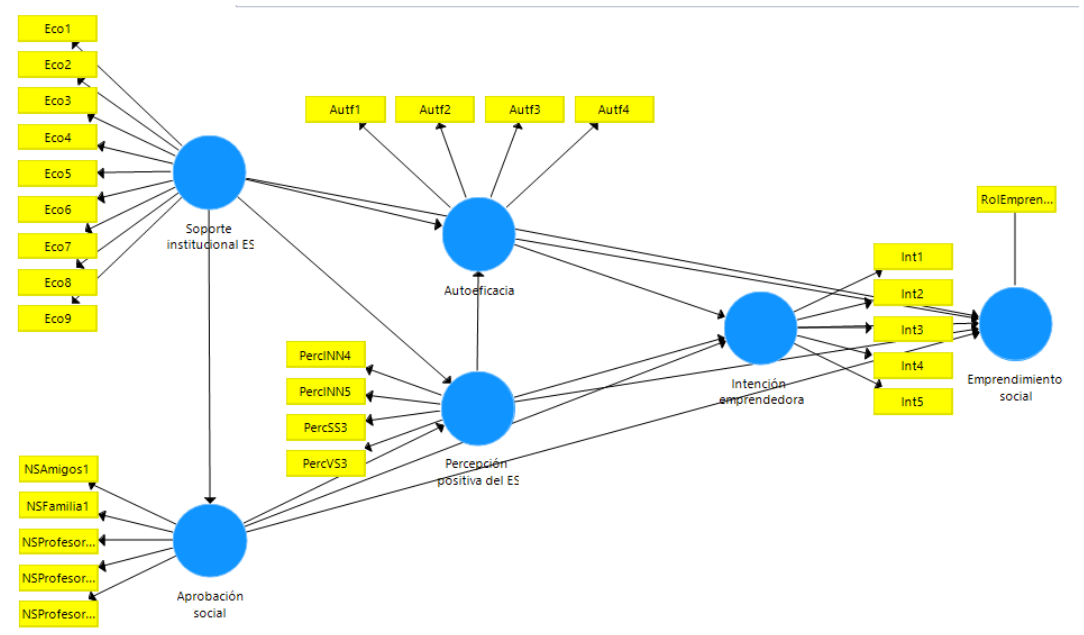

Fuente: Elaboración propia 


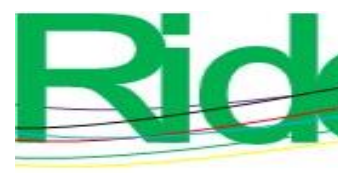

Revista Iberoamericana para la
Investigación y el Desarrollo Educativo
ISSN $2007-7467$

El cambio en el modelo local respecto a la investigación original implica que la universidad objeto de investigación no está haciendo suficiente trabajo ni dando el apoyo para fomentar y acompañar el proceso de emprender, pues es menor a $1 \%$ el porcentaje de líderes de emprendimiento, queda muy lejos de la cifra de $12.7 \%$ encontrada por la Instituto Nacional del Emprendedor (2016) (aunque cabe precisar que los jóvenes entre 18 y 24 años mencionados no son específicamente universitarios). Y también muy por debajo del $3.4 \%$ de la investigación a nivel internacional.

\section{Conclusiones}

De acuerdo con el propósito del presente estudio, que fue comparar un estudio internacional sobre emprendimiento social de base universitaria en América Latina con el contexto de la Universidad Autónoma de Zacatecas, específicamente su Unidad Académica de Contaduría y Administración, ya que se consideró que al generalizar los resultados encontrados en las 26 universidades de ocho países se puede caer en el error de tomar decisiones equivocadas basadas en los mencionados resultados, se encontraron resultados diferentes en cuanto a los estadísticos descriptivos, pues solamente $0.7 \%$ lidera proyectos de emprendimiento social, aún más bajo que la cifra de $3.4 \%$ encontrada en el estudio internacional. Respecto al modelo, al evaluar el modelo de medida, o outer model, se eliminaron ítems que no alcanzaron en su carga externa al menos el 0.4 que se requiere como mínimo para conservarlo. Se trata de otra de las diferencias más significativas del contexto, pues, de los constructos de aprobación social y percepción positiva del emprendimiento social, se eliminaron dos y siete ítems respectivamente, lo que indica que la visión que tienen los alumnos sobre emprender se ajusta a diferentes motivos en los distintos contextos, y los dotan de un peso específico desigual. A pesar de que el modelo estructural no presentó diferencias, lo que comprueba que el modelo se apega al original, no se obtuvieron los mismos valores. Para la presente investigación, destaca una intención emprendedora muy fuerte (0.43), pero un emprendimiento tendiente a cero (-.016). El haber efectuado la presente investigación y obtenido los resultados ya mencionados permitirá tomar las decisiones adecuadas en el contexto estudiado por parte de las autoridades universitarias correspondientes, ya que el trabajo actual no refleja resultados de una mentalidad emprendedora por parte de los alumnos. 


\section{Contribuciones a futuras líneas de investigación}

A partir de los resultados obtenidos en la presente investigación, se deben implementar acciones por parte de la administración y docentes involucrados en la reestructuración del plan de estudios con la finalidad de fomentar el emprendimiento social entre los alumnos, así como darle seguimiento, lo que permitirá tomar decisiones pertinentes de acuerdo con resultados futuros.

\section{Referencias}

Caldera, D., León, S. y Sánchez, M. (2017). Desafíos para el desarrollo de programas y ecosistemas universitarios de emprendimiento en México. Ponencia presentada en el Congreso Interdisciplinario de Cuerpos Académicos. Guanajuato, 28 y 29 de septiembre de 2017.

Cepeda, G., Henseler, J., Ringle, C. M. and Roldán, J. L. (2016). Prediction-oriented modeling in business research by means of PLS path modeling. Journal of Business Research, 69(10), 4545-4551.

Cassel, C., Hackl, P. and Westlund, A. H. (1999). Robustness of partial least-squares method for estimating latent variable quality structures. Journal of Applied Statistics, 26(4), 435-446.

Chin, W.W. (2010). How to Write Up and Report PLS Analyses. In Esposito, V. V., Chin, W., Henseler, J. and Wang, H. (eds.), Handbook of Partial Least Squares. Berlin, Germany: Springer. https://doi.org/10.1007/978-3-540-32827-8_29

Duarte, T. y Ruiz, M. (2009). Emprendimiento, una opción para el desarrollo. Scientia et Technica, 15(43), 326-331. Recuperado de https://www.redalyc.org/pdf/849/84917310058.pdf.

Durán, J. (2016). Emprendimiento juvenil en México. Informe nacional del "estudio de laoferta d recursos técnicos y tecnológicos para favorecer los procesos de emprendimiento juvenil" del CLADCS del INCAE. Recuperado de https://incae.edu.sites/reporte_nacional_-_mexico_final_corregido.pdf (incae.edu)

Fornell, C. and Larcker, D. F. (1981). Evaluating Structural Equation Models with Unobservable Variables and Measurement Error. Journal of Marketing Research, $18(1), 39-50$.

Gibb, A. (2011). Espíritu empresarial: Soluciones únicas para ambientes únicos. ¿Acaso es posible lograr esto con el paradigma existente? En Varela, R. (ed.), Desarrollo, 

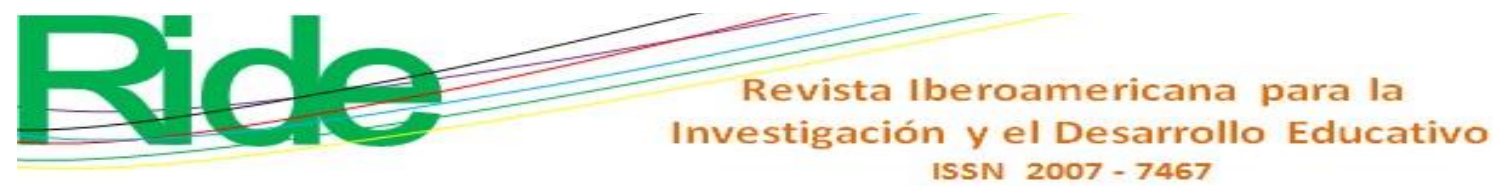

Innovación y Cultura Empresarial. Volumen 2. Educación Empresarial (pp. 15-76). Santiago de Cali, Colombia: Centro de Desarrollo del Espíritu Empresarial.

Giraldo, W. A. y Vara, A. A. (coords.) (2018). El emprendimiento social de base universitaria en Latinoamérica. ¿Están las universidades haciendo lo suficiente? Lima, Perú: Universidad de San Martín de Porres-Accreditation Council for Business Schools and Programs. Recuperado de administracion.usmp.edu.pe/investigacion/files/USMP-ACBSP-LIBROEMPRENDIMIENTO-SOCIAL-COMPLETO.pdf.

González, M. D. (coord.) (2012). Retos de las ciencias administrativas desde las economías emergentes: evolución de sociedades. México: Instituto Tecnológico y de Estudios Superiores de Monterrey.

Hair, J. F., Hult, G. T. M., Ringle, C. M. and Sarstedt, M. (2007). A Primer on Partial Least Squares Structural Equation Modeling (PLS-SEM) (2 ${ }^{\text {nd }}$ ed.).Thousand Oaks, United States: Sage.

Hair, J. F., Black, W. C., Babin, B. J. and Anderson, R. E. (2010). Multivariate Data Analysis. ( $7^{\text {th }}$ ed.). United States: Prentice Hall.

Henseler, J. and Sarstedt, M. (2013). Goodness-of-fit indices for partial least squares path modelling. Computational Statistics, 28, 565-580.

Henseler, J., Ringle, C. M. and Sarstedt, M. (2015). A New Criterion for Assessing Discriminant Validity in Variance-Based Structural Equation Modeling. Journal of the Academy of Marketing Science, 43(1), 115-135.

Hernández, C. y Arano, R. (2015). El desarrollo de la cultura emprendedora en estudiantes universitarios para el fortalecimiento de la visión empresarial. Revista Ciencia Administrativa, (2015-1), 29-37. Recuperado de https://www.uv.mx/iiesca/files/2012/10/04CA201501.pdf.

Hernández, R., Fernández, C. y Baptista, P. (2014). Metodología de la investigación (6. ${ }^{a}$ ed.). Ciudad de México, México: McGraw-Hill.

Hidalgo, G., Kamiya, M. y Reyes, M. (2014). Emprendimientos dinámicos en América Latina. Avances en prácticas y políticas. Caracas, Venezuela: Banco de Desarrollo de América Latina. Recuperado de http://scioteca.caf.com/handle/123456789/371.

Instituto Nacional del Emprendedor. (2016). Diagnóstico 2016 del Fondo Nacional Emprendedor. México: Secretaría de Economía. Recuperado de 


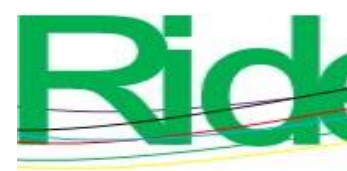

Revista Iberoamericana para la Investigación y el Desarrollo Educativo ISSN $2007-7467$

https://www.inadem.gob.mx/wpcontent/uploads/2017/02/Diagno\%CC\%81stico_FNE-2016-1.pdf.

Landero, H. R. y González, M. T. (2007). Estadística con SPSS y metodología de la investigación. México: Trillas.

Lideres mexicanos. (2016). El emprendimiento en México está en su nivel más alto desde 2001. Reuperado en https://lideresmexicanos.con/noticias/el-emprendimiento-enmexico-esta-en-su-nivel-mas-alto-desde-2001/

Lohmöller, J. B. (1989). Latent Variable Path Modeling with Partial Least Squares. Berlin, Germany: Springer-Verlag.

Lozano, O. y Cayetano, J. (2011). El emprendedor de la empresa familiar mexicana, una visión crítica. Gestión y Estrategia, (40).

Morales, J., Bustamante, A., Vargas, S., Pérez, N. y Sereno, O. (2015). Factores de éxito emprendedor en dos municipios de la montaña de Guerrero, México. Nova Scientia, 7(15), 416-435.

Normas APA. (s. f.). Cuantitativo o cualitativo, ¿cuál escoger? Recuperado de https://normasapa.net/cuantitativo-o-cualitativo-cual-escoger/.

Ojeda, J., Mexicano, A., Mosqueda, M. (2012). Causas de inicio y quiebre de pymes en un municipio de la región Laja-Bajío. Voces de los empresarios. Ponencia presentada en el 6. ${ }^{\circ}$ Coloquio de Investigación Nacional e Internacional de Cuerpos Académicos. Aguascalientes, del 20 al 22 de junio 2012.

Organización Internacional de Trabajo [OIT]. (24 de agosto de 2016). El desempleo juvenil está aumentando de nuevo en el mundo. Comunicado de prensa. Recuperado de http://www.ilo.org/global/about-the-ilo/newsroom/news/WCMS_513736/lang-es/index.htm.

Palomares, D. y Chisvert, M. J. (2014). Ética y empresa en el espacio universitario: el emprendimiento social en las universidades públicas como vehículo facilitador de la equidad social. Revista de Docencia Universitaria, 12(2), 205-230.

Patiño, J. D., Ruiz, A. y Pitre, R. (2018). El emprendimiento en Colombia, una respuesta a los retos de competitividad y desarrollo sostenible. Revista Espacios, 39(14), 24.

Ringle, C. M., Wende, S. and Becker, J. M. (2015). SmartPLS 3. Bönningstedt, Germany: SmartPLS. Retrieved from http://www.smartpls.com.

Santander, V. (2010). Características del comportamiento emprendedor en alumnos de enseñanza media de la ciudad de Talca. UCMaule - Revista Académica, (39), 91-114. 

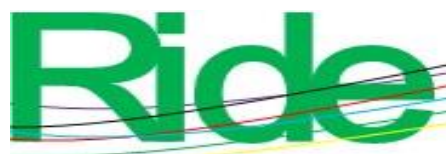

Revista Iberoamericana para la Investigación y el Desarrollo Educativo ISSN $2007-7467$

Sarstedt, M., Ringle, C. M. and Hair, J. (2017). Partial Least Squares Structural Equation Modeling. In Homburg, C., Klarmann, M. and Vomberg, A. (eds.), Handbook of Market Research. New York, United States: Springer.

Sistema de Información Legislativa de la Secretaría de Gobernación. (2016). Que expide la Ley General de Promoción e Impulso al Joven Emprendedor, a cargo del diputado Luis Fernando Antero Valle, del grupo parlamentario del PAN. Recuperado de http://sil.gobernacion.gob.mx/Archivos/Documentos/2016/04/asun_3371822_20160 426_1460479045.pdf.

Tarapuez, E. y Botero, J. (2007). Algunos aportes de los neoclásicos a la teoría del emprendedor. Cuadernos de Administración, 20(34), 39-63.

Tenenhaus, M., Esposito, V., Chatelin, Y. M. and Lauro, C. (2005). PLS path modeling. Computational Statistics \& Data Analysis, 48(1), 159-205. 


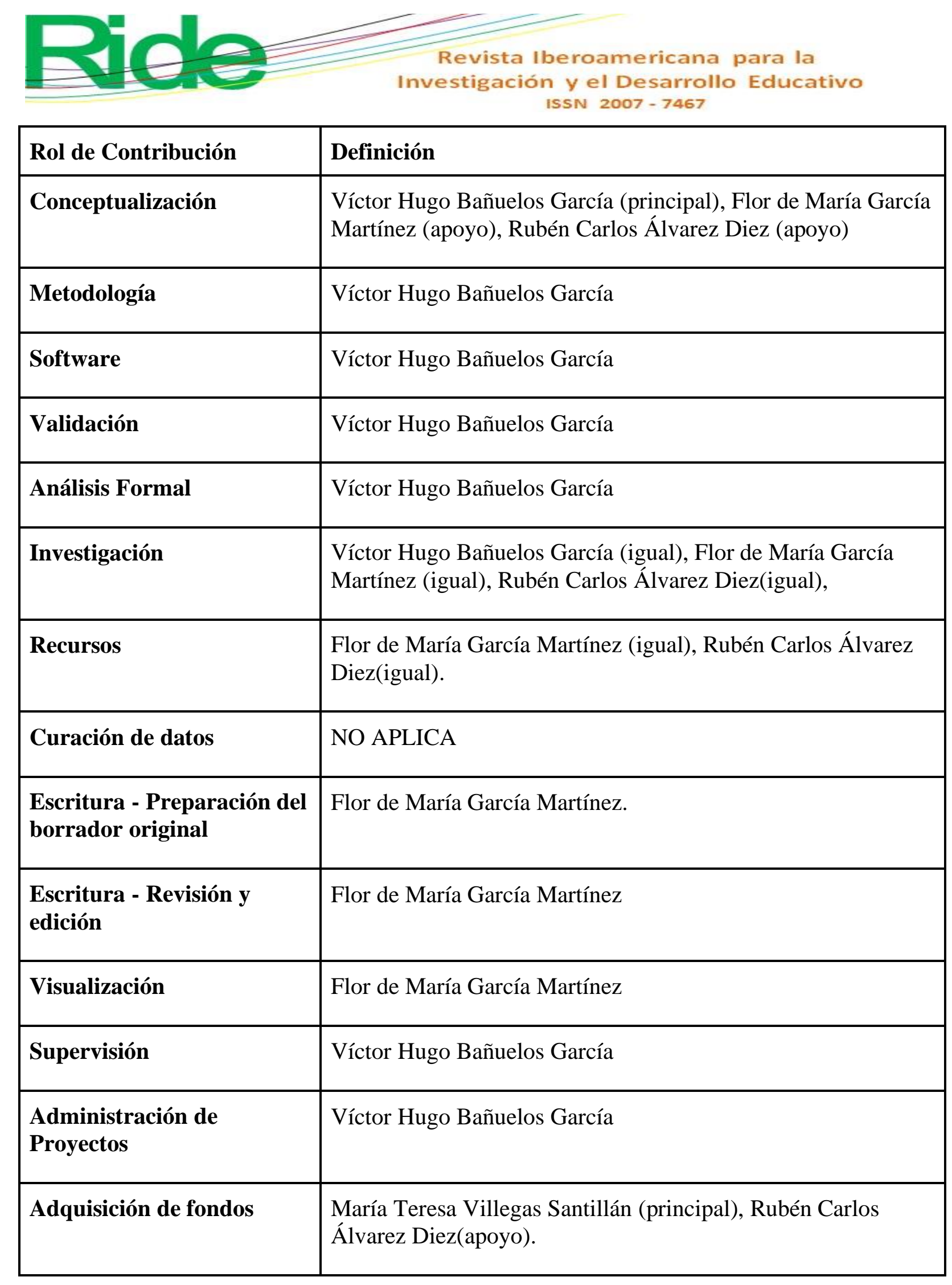

